RESEARCH AND PRACTICE

\title{
Factors associated with body mass index among African American breast cancer survivors
}

Selina A. Smith, PhD, MDivi,2,3, Mechelle D. Claridy, MPH, ${ }^{4,5}$, Mary S. Whitehead, MPH, CHES ${ }^{3}$, Joyce Q. Sheats, $\mathrm{MPH}^{1}$,Wonsuk Yoo, $\mathrm{PhD}^{1,6}$, Ernest Alema-Mensah, PhD, DMin ${ }^{4,5}$, Benjamin E. Ansa, MD, MSCR ${ }^{1}$ and Ronald L. Braithwaite, $\mathrm{PhD}^{4,7}$

\begin{abstract}
${ }^{1}$ Institute of Public \& Preventive Health, Augusta University, Augusta, GA; ${ }^{2}$ Department of Family Medicine, Medical College of Georgia, Augusta University, Augusta, GA; ${ }^{3}$ SISTAAH Talk Breast Cancer Support Group, Miami, FL; ${ }^{4}$ Department of Community Health and Preventive Medicine, Morehouse School of Medicine, Atlanta, GA; ${ }^{5}$ Cancer Research Program, Morehouse School of Medicine, Atlanta, GA; ${ }^{6}$ Dental College of Georgia, Augusta University, Augusta, GA; and ${ }^{7}$ Department of Family Medicine, Morehouse School of Medicine, Atlanta, GA
\end{abstract}

\begin{abstract}
Background: Weight gain after diagnosis and treatment is common among breast cancer survivors (BCSs). Little information exists regarding associations between body mass index (BMI) and lifestyle factors and health-related quality of life (HR-QoL) among African American (AA) BCSs. The present study sought to determine associations between BMI, dietary intake, and physical activity as lifestyle modification strategies and HR-QoL among AA BCSs.
\end{abstract}

Methods: For this cross-sectional study, a lifestyle assessment tool was administered to 195 AA BCSs. Possible predictor variables included socio-demographic and medical characteristics, dietary intake and physical activity patterns, and physical health. The outcome variable was BMI.

Results: Many BCSs (63\%) had BMIs $\geq 25 \mathrm{Kg} / \mathrm{M}^{2}$ and presented with stage I cancer (41\%) at diagnosis. Among those presenting with late-stage cancer (IIIA, IIIB, IV), $76 \%$ were overweight or obese $(p=0.0008)$. Eighty-four percent reported excellent-to-good physical health $(\mathrm{p}=0.0499)$ and were less likely to have higher BMIs compared to those reporting fair-topoor physical health $(\mathrm{OR}=0.616$ [CI=0.192-1.978]). Responders with graduate level education were more likely to have healthy body weights than those attaining high school or less educational levels (OR=2.379 [CI=0.617-9.166]).

Conclusions: Most AA BCSs surveyed were overweight or obese, did not engage in recommended physical activity levels and failed to consume diets linked to breast cancer prevention. Interventions are needed to promote weight loss, improve dietary intake, and enhance physical activity among AA BCSs.

Key Words: Body mass index; dietary intake, physical activity, HR-QoL, cancer survivors

\section{INTRODUCTION}

In 2014, there were more than 3.1 million breast cancer survivors (BCSs) in the United States, accounting for about $21 \%$ of the total cancer survivors (American Cancer Society (ACS), 2015). Weight gain after diagnosis and treatment is common among women with breast cancer (Irwin, et al. 2005) and is associated with poorer outcomes, including poorer quality of life, increased recurrence, breast cancer deaths, and all-cause mortality (Demark- Wahnefried, Campbell \& Hayes, 2012). A sustained loss of $10 \%$ of initial weight may reduce risk of recurrence of new primary breast cancers (Chlebowski, Aiello \& McTiernan, 2002; Ansa, Yoo, Whitehead, Coughlin, \& Smith, 2015). Possible factors for weight gain include fatigue and reduced physical activity, reductions in lean body mass and resting energy expenditure, overeating as a means to cope, and/or treatment-related increases in appetite (Kroenke, Chen, Rosner \& Holmes, 2005).
For many chronic diseases, physical exercise improves quality of life and reduces all-cause mortality (Döring, Pfueller, Paul, \& Dörr, 2012; Heran, et al. 2011; Atlantis, Chow, Kirby \& Singh, 2004). Physical activity may be an effective intervention for enhancing quality of life and overall survival, since moderate levels reduce the risk of breast cancer death (Holmes, Chen, Feskanich, Kroenke \& Colditz, 2005; McNeely, et al. 2006; Brown, Winters-Stone, Lee \& Schmitz, 2012).

There is now considerable interest in health-related quality of life (HR-QoL) of BCSs. HR-QoL is a broad, multidimensional concept that usually includes subjective evaluations of both positive and negative aspects of life (Centers for Disease Control and Prevention (CDC)). HRQoL constructs include measures of overall health, physical health, mental health, and social functioning.

Since BCSs are heterogeneous in their demographic profile (e.g., age, race/ethnicity, level of education, and socioeconomic status), behavioral profile (e.g., smoking status, alcohol consumption, and obesity), disease 
pathophysiology, treatment protocols, symptoms, side effects, and HR-QoL constructs (McNeely, et al. 2006), summarizing the lifestyle risk factors and performance of HR-QoL studies across such a disparate group may be difficult. Nevertheless, racial-ethnic disparities in modifiable breast cancer risk factors (obesity, physical inactivity, and low consumption of fruits and vegetables) are large and persistent, especially between White and African American (AA) women (Halbert, et al. 2008). Data from the Behavioral Risk Factor Surveillance System (BRFSS) revealed that AA women, compared to White women, are more likely to be obese ( $57.6 \%$ vs. $32.8 \%)$; consume less fruits and vegetables (12.6\% vs. $17.4 \%)$; and to be physically inactive (63.8\% vs. 50.9\%) (CDC, 2007; National Center for Health Statistics, 2015; Vásquez, Shaw, Gensburg, Okorodudu \& Corsino, 2013). AA BCSs are also underrepresented in research targeting lifestyle modifications. Results from one of the few studies with their inclusion, the Women's Healthy Eating and Living (WHEL) Study, found that, at baseline, AA survivors are more likely than Whites to consume more calories from fat $(+3.2 \%)$ and fewer servings of fruits (-0.7/day) (Paxton, et al. 2011) and are less successful at making and maintaining dietary changes (Paxton, et. al. 2012). This disparity may extend to nonclinical outcomes, including HR-QoL. Relative to their White counterparts, AA women with and without breast cancer have consistent HR-QoL deficits (Matthews, Tejeda, Johnson, Berbaum \& Manfredi, 2012; Bowen, et al. 2007).

For AA women, who have some of the highest obesity rates in this country, effective long-term lifestyle modification is a target for reducing cancer disparities and enhancing prognosis among BCSs. The present study sought to describe the association between dietary intake, physical activity, and HR-QoL, as predictor variables, and body mass index (BMI), as the outcome, in a sample of AA BCSs.

\section{METHODS}

\section{Participants/Data Source}

The research protocol for this study, Assessing lifestyle modification needs and experiences of AA BCSs, has been described elsewhere (Smith, et al. 2015). Briefly, 240 AA BCSs were recruited from Survivors Involving Supporters Taking Action to Advance Health (SISTAAH) Talk, a support group for AA BCSs aimed at mitigating traumatic events (i.e., breast cancer-related concerns, self-reported physical well-being, isolation, loneliness, distress, depression, anxiety, etc.). The purpose of SISTAAH Talk is to provide a forum for AA women to communicate about and make sense of their breast cancer experience in order to achieve improved physical and mental health outcomes. The sampling technique for the recruitment of participants was non-randomized.

A lifestyle assessment tool (LAT), including validated scales related to dietary intake/physical activity, weight loss history, HR-QoL, and cancer risk, was administered to study participants. LAT scales were derived from: 1) the Behavioral Risk Factor Surveillance System (BRFSS) physical activity questionnaire (CDC); 2) the National Health and Nutrition Examination Survey (NHANES) weight history questionnaire (CDC); and 3) the National Health Interview Survey (NHIS) Cancer Control Supplement Questionnaire (CDC). Additional components included demographics, breast cancer diagnosis and treatment history, HR-QoL, weight history, physical activity, and dietary intake. Three modes of administration were used: self-administered online, a mailed copy, and facilitator-administered through a telephone interview.

The Institutional Review Board at Morehouse School of Medicine approved the study protocol. Participants received information on the study and consented to participate.

\section{Measures}

There were four self-reported categories of predictor variables: 1) socio-demographics including age (18-34 years, 35-54 years, and 55 years and older); education (high school diploma or less, college, and graduate); income $(\leq \$ 24,999, \$ 25,000-\$ 50,000, \geq \$ 50,000)$; and marital status (single, married, or widowed/divorced); 2) American Joint Committee on Cancer TNM system stage of diagnosis (I, II, IIIA, IIIB, and IV) as obtained from their physicians (BCSs without knowledge of or unwilling to disclose stage of diagnosis were grouped as 'don't know' with recurrence as 'yes,' if BCSs reported having recurrence; 'no', if there was none; or 'don't know,' if the respondent had no knowledge); 3) dietary intake and physical activity assessed by use of NHANES and BRFSS scales; and 4) HR-QoL, captured using the Patient-Reported Outcomes Measurement Information System (PROMIS) Global 10-item Health Scale of HR-QoL domains, including physical and mental health. HR-QoL physical health variables were categorized as good (excellent-to-good) or poor (fair-to-poor). The outcome variable was BMI, defined as weight in kilograms divided by the square of height in meters (CDC). Height and weight were self-reported by participants. BCSs were grouped as 'healthy' (BMI< $25 \mathrm{Kg} / \mathrm{M}^{2}$ ), 'overweight' (BMI= 25-29 $\left.\mathrm{Kg} / \mathrm{M}^{2}\right)$, or 'obese' $\left(\mathrm{BMI} \geq 30 \mathrm{Kg} / \mathrm{M}^{2}\right)$.

\section{Statistical Analyses}

All data from socioeconomic, TNM staging system, dietary intake, and HR-QoL variables were summarized with frequencies and percentages and were compared according to BMI categories using chi-square and Fisher's exact test. A multivariate regression analysis was conducted, modeling those who were overweight or obese by each demographic and clinical variable, and by physical health status. P-values were two-sided, and, if $<0.05$, were considered statistically significant. The analyses were accomplished with SAS statistical software, version 9.2 (SAS Institute, Cary, NC).

\section{RESULTS}

Of the 240 AA BCSs recruited, 45 were excluded for failure to complete the weight and height questions; the overall response rate was $81 \%$. For this present report, 195 AA BCSs, with ages ranging between 18 and $\geq 55$ years, completed the LAT (Table 1). Many were in the $\geq 55$ years age group (59.4\%), had college education (62.7\%), had an annual income between $\$ 25,000$ and $\$ 50,000$ (35.6\%), and presented with stage I cancer at diagnosis (40.7\%). The age groups 18-34 years and 35-54 years accounted for 3.1\% and 
$37.5 \%$ of the study population, respectively. Thirteen respondents (6.6\%) reported being underweight; since this number was considered too small to have any effect on the statistical analyses, they were included in the 'healthy BMI' group.

Of the BCSs, 37.5\% (including the 13 underweight participants) had BMIs $<25 \mathrm{Kg} / \mathrm{M}^{2}$, 31.8\% were overweight
$\left(\mathrm{BMI}=25-29 \mathrm{Kg} / \mathrm{M}^{2}\right.$ ), and $30.7 \%$ were obese (BMI >30 $\mathrm{Kg} / \mathrm{M}^{2}$ ) (Table1). Forty-one (21.7\%) reported late-stage breast cancer (IIIA, IIIB, or IV), and 128 (67.7\%) had stages I or II. Of those with late-stage disease, $75.6 \%$ had BMIs $\geq 25 \mathrm{Kg} / \mathrm{M}^{2}(\mathrm{P}=0.0008)$. Although there was no statistically significant association between breast cancer recurrence and BMI status, $77 \%$ reporting a recurrence had high BMIs compared to $59 \%$ of those who did not $(\mathrm{p}=0.2816)$.

Table 1. Descriptive Characteristics of AA BCSs by BMI* Status after Breast Cancer Treatment

\begin{tabular}{|c|c|c|c|c|c|}
\hline Variable & $\begin{array}{c}\text { Total } \\
\mathrm{N}=195(100 \%)\end{array}$ & $\begin{array}{c}\text { Healthy } \\
\text { n (\%) }\end{array}$ & $\begin{array}{c}\text { Overweight } \\
\text { n (\%) }\end{array}$ & $\begin{array}{l}\text { Obese } \\
\text { n (\%) }\end{array}$ & p-value** \\
\hline Age (Years) & & & & & 0.8825 \\
\hline $18-34$ & $6(3.1)$ & $3(4.2)$ & $1(1.6)$ & $2(3.4)$ & \\
\hline $35-54$ & $72(37.5)$ & $25(34.7)$ & $23(37.7)$ & $24(40.7)$ & \\
\hline$\geq 55$ & $114(59.4)$ & $44(61.1)$ & $37(60.7)$ & $33(55.9)$ & \\
\hline Income (Annual) & & & & & 0.5913 \\
\hline$\leq \$ 24,999$ & $62(32.5)$ & $18(25.4)$ & $22(36.7)$ & $22(36.6)$ & \\
\hline$\$ 25,000-\$ 50,000$ & $68(35.6)$ & $28(39.4)$ & $21(35.0)$ & $19(31.7)$ & \\
\hline$\geq \$ 50,000$ & $61(31.9)$ & $25(35.2)$ & $17(28.3)$ & $19(31.7)$ & \\
\hline Education & & & & & 0.5798 \\
\hline High school or Less & $42(21.8)$ & $13(18.1)$ & $13(21.3)$ & $16(26.7)$ & \\
\hline College & $121(62.7)$ & $45(62.5)$ & $41(67.2)$ & $35(58.3)$ & \\
\hline Graduate & $30(15.5)$ & $14(19.4)$ & $7(11.5)$ & $9(15.0)$ & \\
\hline Marital Status & & & & & 0.7838 \\
\hline Single & $46(24.0)$ & $15(20.8)$ & $15(25.0)$ & $16(26.7)$ & \\
\hline Married & $72(37.5)$ & $31(43.1)$ & $20(33.3)$ & $21(35.0)$ & \\
\hline Widowed or Divorced & $74(38.5)$ & $26(36.1)$ & $25(41.7)$ & $23(38.3)$ & \\
\hline Stage at Diagnosis & & & & & 0.0008 \\
\hline Stage I & $77(40.7)$ & $34(47.9)$ & $22(37.3)$ & $21(35.6)$ & \\
\hline Stage II & $51(27.0)$ & $14(19.7)$ & $23(38.9)$ & $14(23.7)$ & \\
\hline Stage IIIA, IIIB, IV & $41(21.7)$ & $10(14.1)$ & $9(15.3)$ & $22(37.3)$ & \\
\hline Don't Know & $20(10.6)$ & $13(18.3)$ & $5(8.5)$ & $2(3.4)$ & \\
\hline BC Recurrence & & & & & 0.2816 \\
\hline Yes & 39 (20.3) & $9(12.5)$ & $17(27.9)$ & $13(22.0)$ & \\
\hline No & $150(78.1)$ & $62(86.1)$ & $43(70.5)$ & $45(76.3)$ & \\
\hline Don't know & $3(1.6)$ & $1(1.4)$ & $1(1.6)$ & $1(1.7)$ & \\
\hline
\end{tabular}

The BMI status of responders correlated with meeting current cancer prevention guidelines (Table 2). The reported number of days consuming vegetables and fruits and engaging in physical activity were not positively correlated to respondents' BMI status. However, more survivors consuming recommended vegetable and fruit servings (44.2\%) and achieving recommended physical activity levels (41.1\%) for at least 12 days per month, had healthier weights than those not meeting cancer prevention guidelines ( $\mathrm{p}=0.2977$ and $\mathrm{p}=0.4311$, respectively).

Table 2. AA BCSs Complying with the Cancer Prevention Guidelines by BMI* Status after Breast Cancer Treatment

\begin{tabular}{|c|c|c|c|c|c|}
\hline Activity & $\begin{array}{c}\text { Total } \\
\mathrm{N}=195(100 \%)\end{array}$ & $\begin{array}{l}\text { Healthy } \\
\text { n (\%) }\end{array}$ & $\begin{array}{c}\text { Overweight } \\
\text { n (\%) }\end{array}$ & $\begin{array}{l}\text { Obese } \\
\text { n }(\%)\end{array}$ & p-value ${ }^{* *}$ \\
\hline $\begin{array}{l}\text { Fruit Servings: Ate fruits in the } \\
\text { past } 30 \text { days }\end{array}$ & & & & & 0.2977 \\
\hline 0 -7 days & $133(68.2)$ & $47(65.3)$ & $41(66.1)$ & 45 (73.8) & \\
\hline 8-11 days & $10(5.1)$ & $2(2.8)$ & $3(4.9)$ & $5(8.2)$ & \\
\hline$\geq 12$ days & $52(26.7)$ & 23 (31.9) & $18(29.0)$ & $11(18.0)$ & \\
\hline $\begin{array}{l}\text { Vegetable Servings: Ate } \\
\text { vegetables in the past } 30 \text { days }\end{array}$ & & & & & 0.7714 \\
\hline 0 -7 days & 134 (68.7) & $52(72.2)$ & $40(64.5)$ & $42(68.8)$ & \\
\hline$\geq 12$ days & $55(28.2)$ & $19(26.4)$ & $19(30.7)$ & 17 (27.9) & \\
\hline
\end{tabular}




\begin{tabular}{|c|c|c|c|c|c|}
\hline Activity & $\begin{array}{c}\text { Total } \\
\mathrm{N}=195(100 \%)\end{array}$ & $\begin{array}{c}\text { Healthy } \\
\text { n (\%) }\end{array}$ & $\begin{array}{c}\text { Overweight } \\
\text { n (\%) }\end{array}$ & $\begin{array}{l}\text { Obese } \\
\text { n (\%) }\end{array}$ & p-value ${ }^{* *}$ \\
\hline Physical Activity & & & & & 0.4311 \\
\hline 0-7days & 139 (71.28) & $49(68.1)$ & $48(77.4)$ & $42(68.9)$ & \\
\hline$\geq 8$ days & $56(28.72)$ & $23(31.9)$ & $14(22.6)$ & $19(31.1)$ & \\
\hline
\end{tabular}

Results for dietary intake and physical activity (Table 3) revealed that $74.4 \%$ of BCSs consumed more red meat and $78.5 \%$ consumed more processed meat than recommended; $<40 \%$ in each of the two groups had normal BMIs $(\mathrm{p}=0.7036$ and $\mathrm{p}=0.1884$, respectively). Fewer responders ate adequate fruits, vegetables, and salads (48.2\%); drank adequate amounts of water (44.1\%); and changed their eating habits (32.8\%) after breast cancer diagnosis. More than half (52.3\%) reported exercising; not eating less sugar, candy, sweets (66.2\%); and not eating less "junk" or "fast" food $(68.2 \%)$.

Table 3. Physical Activity and Dietary Profile of AA BCSs by BMI* Status after Breast Cancer Treatment

\begin{tabular}{|c|c|c|c|c|c|}
\hline Activity & $\begin{array}{c}\text { Total } \\
\mathrm{N}=\mathbf{1 9 5}(100 \%)\end{array}$ & $\begin{array}{l}\text { Healthy } \\
\text { n (\%) }\end{array}$ & $\begin{array}{c}\text { Overweight } \\
\text { n (\%) }\end{array}$ & $\begin{array}{l}\text { Obese } \\
\text { n (\%) }\end{array}$ & $\begin{array}{c}\text { p- } \\
\text { value }\end{array}$ \\
\hline Exercised & & & & & 0.8008 \\
\hline Yes & $102(52.3)$ & $37(51.4)$ & $31(50.0)$ & $34(55.7)$ & \\
\hline No & $93(47.7)$ & $35(48.6)$ & $31(50.0)$ & $27(44.3)$ & \\
\hline Ate Red Meat & & & & & 0.7036 \\
\hline Yes & $145(74.4)$ & $56(77.8)$ & $45(72.6)$ & $44(72.1)$ & \\
\hline No & $50(25.6)$ & $16(22.2)$ & $17(27.4)$ & $17(27.9)$ & \\
\hline Ate processed meat & & & & & 0.1884 \\
\hline Yes & $153(78.5)$ & $59(81.9)$ & $51(82.3)$ & $43(70.5)$ & \\
\hline No & $42(21.5)$ & $13(18.1)$ & $11(17.7)$ & $18(29.5)$ & \\
\hline Chose whole grain & & & & & 0.6693 \\
\hline Yes & $159(81.5)$ & $61(84.7)$ & $49(79.0)$ & $49(80.3)$ & \\
\hline No & $36(18.5)$ & $11(15.3)$ & $13(21.0)$ & $12(19.7)$ & \\
\hline $\begin{array}{l}\text { Ate "Diet" foods or } \\
\text { Products }\end{array}$ & & & & & 0.6967 \\
\hline Yes & $21(10.8)$ & $8(11.1)$ & $8(12.9)$ & $5(8.2)$ & \\
\hline No & $174(89.2)$ & $64(88.9)$ & $54(87.1)$ & $56(91.8)$ & \\
\hline $\begin{array}{l}\text { Drank adequate amounts } \\
\text { of water }\end{array}$ & & & & & 0.8014 \\
\hline Yes & $86(44.1)$ & $31(43.1)$ & $26(41.9)$ & $29(47.5)$ & \\
\hline No & 109 (55.9) & $41(56.9)$ & $36(58.1)$ & $32(52.5)$ & \\
\hline $\begin{array}{l}\text { Ate less sugar, candy, } \\
\text { sweets }\end{array}$ & & & & & 0.4786 \\
\hline Yes & $66(33.8)$ & 24 (33.3) & $18(29.0)$ & 24 (39.3) & \\
\hline No & $129(66.2)$ & $48(66.7)$ & $44(71.0)$ & $37(60.7)$ & \\
\hline $\begin{array}{l}\text { Ate more fruits, } \\
\text { vegetables, salad }\end{array}$ & & & & & 0.6110 \\
\hline Yes & $94(48.2)$ & $35(48.6)$ & $27(43.5)$ & $32(52.5)$ & \\
\hline No & $101(51.8)$ & $37(51.4)$ & 35 (56.5) & $29(47.5)$ & \\
\hline Changed eating habits & & & & & 0.8738 \\
\hline Yes & $64(32.8)$ & $22(30.6)$ & $21(33.9)$ & $21(34.4)$ & \\
\hline No & $131(67.2)$ & $50(69.4)$ & $41(66.1)$ & $40(65.6)$ & \\
\hline $\begin{array}{l}\text { Ate less 'junk food' or } \\
\text { 'fast food' }\end{array}$ & & & & & 0.3663 \\
\hline Yes & $62(31.8)$ & $23(31.9)$ & $16(25.8)$ & $23(37.7)$ & \\
\hline No & $133(68.2)$ & $49(68.1)$ & $46(74.2)$ & $38(62.3)$ & \\
\hline
\end{tabular}

Most survivors reported excellent-to-good HR-QoL. The association of BMI status with the physical health component of HR-QoL was statistically significant (Table 4). Of respondents with excellent-good physical health, $78.9 \%$ had normal BMI values, compared to $21.1 \%$ with fair-to-poor physical health $(\mathrm{p}=0.0499)$. BCSs with excellent-to-good overall quality of life $(87.5 \%$; $\mathrm{p}=0.1227)$ and excellent-to-good physical functioning (90.1\%, $\mathrm{p}=0.9190$ ) had healthy BMI values. 
Table 4. Physical Health HR-QoL by BMI* Status after Breast Cancer Treatment

\begin{tabular}{|c|c|c|c|c|c|}
\hline Measure & $\begin{array}{c}\text { Total } \\
\mathrm{N}=195(100 \%)\end{array}$ & $\begin{array}{c}\text { Healthy } \\
\text { n (\%) }\end{array}$ & $\begin{array}{c}\text { Overweight } \\
\text { n (\%) }\end{array}$ & $\begin{array}{l}\text { Obese } \\
\text { n (\%) }\end{array}$ & p-value \\
\hline Overall Quality of Life & & & & & 0.1227 \\
\hline Excellent-Good & $180(92.3)$ & $63(87.5)$ & $60(33.3)$ & $57(31.7)$ & \\
\hline Fair-Poor & $15(7.7)$ & $9(12.5)$ & $2(13.3)$ & $4(26.7)$ & \\
\hline Physical Health & & & & & 0.0499 \\
\hline Excellent-Good & $162(84.4)$ & 56 (78.9) & $58(93.5)$ & $48(81.4)$ & \\
\hline Fair-Poor & $30(15.6)$ & $15(21.1)$ & $4(6.5)$ & 11 (18.6) & \\
\hline Physical Functioning & & & & & 0.9190 \\
\hline Excellent-Good & $177(91.2)$ & $64(90.1)$ & 57 (91.9) & $56(91.8)$ & \\
\hline Fair-Poor & $17(8.8)$ & $7(9.9)$ & $5(8.1)$ & $5(8.2)$ & \\
\hline
\end{tabular}

Use of a stratified multivariate model for those with BMIs $\geq 25 \mathrm{Kg} / \mathrm{M}^{2}$, with adjustments for demographic, clinical, and HR-QoL variables (Table 5), revealed that age $<35$ years $(\mathrm{OR}=0.140$ [CI: 0.010-2.019]), lower income $\leq \$ 25,000$ (OR=0.693 [CI: 0.252-1.901]), and being married $(\mathrm{OR}=$ 0.677 [CI: 0.237-1.935]) were protective factors against high BMIs. Survivors reporting excellent-to-good physical health and physical functioning were also less likely to be overweight or obese $(\mathrm{OR}=0.616$ [CI: 0.192-1.978]; and $\mathrm{OR}=0.4212$ [CI: 0.130-1.299] respectively). Lower level education and breast cancer recurrence were risk factors for high BMIs; BCSs with high school education or less were
2.4 times (C.I: $0.617-9.166)$ more likely to have BMIs $\geq 25$ $\mathrm{Kg} / \mathrm{M}^{2}$ than those with graduate level education, and those reporting recurrence were 1.4 times (CI: 0.495-4.114) more likely to have higher BMIs than survivors who did not. BCSs reporting excellent-to-good overall HR-QoL were more likely to have BMIs $\geq 25 \mathrm{Kg} / \mathrm{M}^{2}$ than those who reported fair-to-poor HR-QoL (OR=3.645 [C.I: 0.77517.132]). All of the odds ratios reported were not statistically significant. The wide confidence interval for overall HR-QoL is a result of the unbalanced frequencies between the comparison groups.

\begin{tabular}{|c|c|c|}
\hline \multirow[b]{2}{*}{ Variables } & \multicolumn{2}{|c|}{ Overweight or Obese After BC Treatment } \\
\hline & Odds Ratio & 95\% Confidence Interval \\
\hline \multicolumn{3}{|l|}{ Age (Years) } \\
\hline $18-34$ years vs. $\geq 55$ years & 0.140 & $0.010-2.019$ \\
\hline $35-54$ years vs. $\geq 55$ years & 0.606 & $0.299-1.226$ \\
\hline \multicolumn{3}{|l|}{ Income (Annual) } \\
\hline$\leq \$ 24,999$ vs. $\geq \$ 50,000$ & 0.693 & $0.252-1.901$ \\
\hline$\$ 25,000-\$ 50,000$ vs. $\geq \$ 50,000$ & 0.959 & $0.404-2.275$ \\
\hline \multicolumn{3}{|l|}{ Education } \\
\hline High school or Less vs. Graduate & 2.379 & $0.617-9.166$ \\
\hline College vs. Graduate & 1.671 & $0.651-4.286$ \\
\hline \multicolumn{3}{|l|}{ Marital Status } \\
\hline Married vs. Single & 0.677 & $0.237-1.935$ \\
\hline Divorced/Widowed vs. Single & 0.974 & $0.370-2.568$ \\
\hline \multicolumn{3}{|l|}{ Recurrence } \\
\hline Yes vs. No & 1.427 & $0.495-4.114$ \\
\hline \multicolumn{3}{|l|}{ Physical Activity (Exercised) } \\
\hline Yes vs. No & 1.125 & $0.315-4.019$ \\
\hline \multicolumn{3}{|l|}{ Overall Quality of Life } \\
\hline Excellent-Good vs. Fair-Poor & 3.645 & $0.775-17.132$ \\
\hline \multicolumn{3}{|l|}{ Physical Health } \\
\hline Excellent-Good vs. Fair-Poor & 0.616 & $0.192-1.978$ \\
\hline \multicolumn{3}{|l|}{ Physical Functioning } \\
\hline Excellent-Good vs. Fair-Poor & 0.412 & $0.130-1.299$ \\
\hline
\end{tabular}




\section{DISCUSSION/CONCLUSIONS}

Most of the participants were overweight/obese (63\%). For this group of survivors, the overweight/obesity rate was 615 per 1000 BCSs. A mediator for weight gain was stage at breast cancer diagnosis $(\mathrm{P}=0.0008)$. Three fourths $(75.6 \%)$ of survivors who presented with stages IIIA, IIIB, or IV at diagnosis had high BMIs. Weight status was not significantly influenced by age, income, education, or marital status; however, not being married and reporting breast cancer recurrence were linked to higher BMIs.

High consumption of red meat and processed meat is a risk factor for breast cancer (Guo, Wei, \& Zhan, 2015). Three quarters of the study population reported consuming more than the recommended servings of red meat and processed meat, and were overweight/obese. Most reported unhealthy habits, such as consuming sweets and 'junk foods.' Engaging in the recommended levels of physical activity and fruit/vegetable consumption are protective against high BMIs (Kushi, et al. 2012); however, in this study, $71 \%$ of survivors reported not engaging in the recommended physical activity levels. Physical activity rates reported for BCSs (Irwin, et al. 2004) and among healthy US women (Kruger, Kohl III \& Miles, 2007) are 32\% and 49.7\%, respectively.

Lower levels of physical activity and higher rates of weight gain/obesity among AA BCSs constitute public health challenges, for obesity and weight gain are negative prognostic indicators of survival (Rock \& DemarkWahnefried, 2002; McTiernan, Irwin, \& VonGruenigen, 2010). After a breast cancer diagnosis, body composition affects clinical outcome, with women who are obese at diagnosis having a 1.5 to 2.5 increased risk of recurrence and death relative to normal-weight survivors (Chlebowski, Aiello \& McTiernan, 2002; Cleveland, et al. 2007). In this study, breast cancer recurrence was not significantly associated with higher BMI $(\mathrm{p}=0.2816)(\mathrm{OR}=1.427[\mathrm{C} . \mathrm{I}$ : 0.495-4.114]).

Results were statistically significant in only the physical health component of HR-QoL based on BMI status $(p=0.0499)$. This finding is similar to results from the WHEL Study (Paxton, et. al. 2012) with few statistically significant results in HR-QoL outcomes by obesity status among AA BCSs. Possible explanations for this lack of association is that many AA women were overweight or obese before their breast cancer diagnosis and/or that cultural norms promote acceptance of higher weights (Ganz, Rowland, Desmond, Meyerowitz, \& Wyatt, 1998; Ashing- Giwa, Ganz \& Petersen, 1999). This may explain why BCSs reporting excellent-to-good overall physical health were 3.7 times more likely to have BMIs $\geq 25 \mathrm{Kg} / \mathrm{M}^{2}$ relative to their counterparts reporting fair-to-poor overall physical health.

Both nationally and in Georgia, AA women of all age groups are more likely than any other ethnic group to die from breast cancer (ACS). Effective, long-term lifestyle modifications are an approach for reducing cancer disparities and enhancing prognoses among AA women. Although culturally-specific interventions have met with some success for weight loss among AA women, there is a need to implement behavioral strategies for long-term and sustained behavioral change. Since the concept of "one size fits all” may not be effective, tailored approaches are recommended. Moreover, governmental environmental policy initiatives, such as safe walking trails and bicycle paths, may enhance community engagement by providing opportunities for promotion of health. Recreational programs sponsored by city or county governments can foster an improved quality of life for local citizens.

This study has several strengths. It is among the few population-based studies examining physical and dietary activity levels and the burden of overweight/obesity among BCSs and also examining these measures solely in AA women. Limitations include self-reporting and possible recall bias. Utilization of a cross-sectional design limits generalizability of results to other groups of BCSs and reduces the possibility of determining causality. Since the number of stage IV survivors was small, these were together grouped with stage III survivors for more accurate statistical analyses. This study did not utilize medical records to capture hormone receptor status or menopausal status of survivors. This information would be useful because hormone receptor-positive and postmenopausal patients tend to have high BMIs (Santa-Maria, Yan, Xie \& Euhus, 2015). Since this was a cross-sectional study, survivors were not followed for long periods to measure change in BMI status. Despite these limitations, this work profiled dietary factors, physical activity, and HR-QoL patterns of a vulnerable group at risk for disparities in BMI and disease outcomes.

Additional research is needed to explain the lack of adherence to cancer prevention guidelines among AA BCSs. Culturally-relevant physical activity and dietary intake interventions may prove beneficial in promoting lifestyle changes.

\section{Acknowledgements}

This work was funded by the National Institute on Minority Health and Health Disparities (1P20MD006881) and the National Cancer Institute (1R01CA166785 and 5U54CA118638-07).

\section{References}

American Cancer Society. Cancer treatment and survivorship Facts \& Figures 2014-2015. Available online:

http://www.cancer.org/acs/groups/content/@research/documents /document/acspc-042801.pdf Accessed December 15, 2015.

American Cancer Society. Breast cancer facts \& figures 20132014. Available online:

http://www.cancer.org/acs/groups/content/@research/documents /document/acspc-042725.pdf Accessed December 29, 2015.

Ansa B, Yoo W, Whitehead M, Coughlin S, Smith S. Beliefs and Behaviors about Breast Cancer Recurrence Risk Reduction among African American Breast Cancer Survivors. International Journal of Environmental Research and Public Health. 2015;13(1):46.

Ashing- Giwa K, Ganz PA, Petersen L. Quality of life of African- American and white long term breast carcinoma survivors. Cancer. 1999;85(2):418-426.

Atlantis E, Chow C-M, Kirby A, Singh MF. An effective exercisebased intervention for improving mental health and quality of life measures: a randomized controlled trial. Preventive Medicine. 2004;39(2):424-434. 
Bowen DJ, Alfano CM, McGregor BA, et al. Possible socioeconomic and ethnic disparities in quality of life in a cohort of breast cancer survivors. Breast Cancer Research and Treatment. 2007;106(1):85-95

Brown JC, Winters-Stone K, Lee A, Schmitz KH. Cancer, Physical Activity, and Exercise. Comprehensive Physiology. 2012;2(4):2775-2809.

Centers for Disease Control and Prevention. Health Related Quality of Life. Available online: http://www.cdc.gov/hrqol/concept.htm Accessed December 15, 2015.

Centers for Disease Control and Prevention. Prevalence of fruit and vegetable consumption and physical activity by race/ethnicity--United States, 2005. MMWR. Morbidity and Mortality Weekly Report. 2007;56(13):301.

Centers for Disease Control and Prevention. BRFSS Questionnaires. Available online: http://www.cdc.gov/brfss/questionnaires/ Accessed February 2, 2013

Centers for Disease Control and Prevention. NHANES 2009-2010 Questionnaire Data. Available online: http://wwwn.cdc.gov/nchs/nhanes/search/datapage.aspx?Compo nent=Questionnaire\&CycleBeginYear=2009 Accessed February 2, 2013.

Centers for Disease Control and Prevention. NHIS. Questionnaires, Datasets, and Related Documentation 1997 to the Present.

Available online:

http://www.cdc.gov/nchs/nhis/quest_data_related_1997_forward .htm Accessed February 2, 2013.

Centers for Disease Control and Prevention. About Adult BMI. Available online

http://www.cdc.gov/healthyweight/assessing/bmi/adult_bmi/ Accesses December 15, 2015.

Chlebowski RT, Aiello E, McTiernan A. Weight loss in breast cancer patient management. Journal of Clinical Oncology. 2002;20(4):1128-1143.

Cleveland RJ, Eng SM, Abrahamson PE, et al. Weight gain prior to diagnosis and survival from breast cancer. Cancer Epidemiology Biomarkers \& Prevention. 2007;16(9):1803-1811.

Demark- Wahnefried W, Campbell KL, Hayes SC. Weight management and its role in breast cancer rehabilitation. Cancer. 2012;118(S8):2277-2287.

Döring A, Pfueller CF, Paul F, Dörr J. Exercise in multiple sclerosis -- an integral component of disease management. The EPMA Journal. 2012;3(1):2.

Ganz PA, Rowland JH, Desmond K, Meyerowitz BE, Wyatt GE. Life after breast cancer: understanding women's health-related quality of life and sexual functioning. Journal of Clinical Oncology. 1998;16(2):501-514.

Guo J, Wei W, Zhan L. Red and processed meat intake and risk of breast cancer: a meta-analysis of prospective studies. Breast Cancer Research and Treatment. 2015;151(1):191-198.

Halbert CH, Weathers B, Esteve R, Audrain-McGovern J, Kumanyika S, DeMichele A, et al. Experiences with weight change in African-American breast cancer survivors. Breast Journal. 2008;14(2):182-187.

Heran BS, Chen JM, Ebrahim S, et al. Exercise-based cardiac rehabilitation for coronary heart disease. The Cochrane database of systematic reviews. 2011;(7):CD001800.
Holmes MD, Chen WY, Feskanich D, Kroenke CH, Colditz GA. Physical activity and survival after breast cancer diagnosis. Jama. 2005;293(20):2479-2486.

Irwin ML, McTiernan A, Bernstein L, et al. Physical activity levels among breast cancer survivors. Medicine and Science in Sports and Exercise. 2004;36(9):1484.

Irwin ML, McTiernan A, Baumgartner RN, et al. Changes in body fat and weight after a breast cancer diagnosis: influence of demographic, prognostic, and lifestyle factors. Journal of Clinical Oncology. 2005;23(4):774-782.

Kroenke CH, Chen WY, Rosner B, Holmes MD. Weight, weight gain, and survival after breast cancer diagnosis. Journal of Clinical Oncology. 2005;23(7):1370-1378.

Kruger J, Kohl III H, Miles I. Prevalence of regular physical activity among adults-United States, 2001 and 2005. Morbidity and Mortality Weekly Report. 2007;56(46):1209-1212.

Kushi LH, Doyle C, McCullough M, et al. American Cancer Society guidelines on nutrition and physical activity for cancer prevention. CA: a Cancer Journal for Clinicians. 2012;62(1):3067.

Matthews AK, Tejeda S, Johnson TP, Berbaum ML, Manfredi C. Correlates of Quality of Life among African American and White Cancer Survivors. Cancer Nursing. 2012;35(5):355-364.

McNeely ML, Campbell KL, Rowe BH, Klassen TP, Mackey JR, Courneya KS. Effects of exercise on breast cancer patients and survivors: a systematic review and meta-analysis. Canadian Medical Association Journal. 2006;175(1):34-41.

McTiernan A, Irwin M, VonGruenigen V. Weight, physical activity, diet, and prognosis in breast and gynecologic cancers. Journal of Clinical Oncology. 2010;28(26):4074-4080.

National Center for Health Statistics. Health, United States, 2014: With Special Feature on Adults Aged 55-64. Hyattsville, MD. 2015.

Paxton RJ, Jones LA, Chang S, et al. Was Race a Factor in the Outcomes of the Women's Health Eating and Living Study? Cancer. 2011;117(16):3805-3813.

Paxton RJ, Phillips KL, Jones LA, Chang S, Taylor WC, Courneya $\mathrm{KS}$, et al. Associations among physical activity, body mass index, and health-related quality of life by race/ethnicity in a diverse sample of breast cancer survivors. Cancer. 2012;118(16):4024-4031.

Patient-Reported Outcomes Measurement Information System (PROMIS). Available online: http://www.nihpromis.org/Documents/PROMISStandards_Vers 2.0_Final.pdf Accessed February 2, 2013.

Rock CL, Demark-Wahnefried W. Nutrition and survival after the diagnosis of breast cancer: a review of the evidence. Journal of Clinical Oncology. 2002;20(15):3302-3316.

Santa-Maria CA, Yan J, Xie X-J, Euhus DM. Aggressive estrogenreceptor-positive breast cancer arising in patients with elevated body mass index. International Journal of Clinical Oncology. 2015;20(2):317-323.

Smith SA, Claridy MD, Whitehead MS, et al. Lifestyle Modification Experiences of African American Breast Cancer Survivors: A Needs Assessment. JMIR Cancer. 2015;1 (2):e9.

Vásquez E, Shaw BA, Gensburg L, Okorodudu D, Corsino L. Racial and Ethnic Differences in Physical Activity and Bone Density: National Health and Nutrition Examination Survey, 2007-2008. Preventing Chronic Disease 2013;10:130183. 